\title{
What false-negative rates of non-invasive testing are active surveillance patients and uro-oncologists willing to accept in order to avoid prostate biopsy?
}

\author{
Rashid Khalid Sayyid, MD'; Dharmendra Dingar, PhD'; Katherine Fleshner, MD²; Taylor Thorburn, MD; \\ Joshua Diamond, MD'; Erik Yao, MD'; Karen Hersey, MD'; Karen Chadwick, MD'; Nathan Perlis, MD'; \\ Laurence Klotz, MD'; Antonio Finelli, MD'; Robert Hamilton, MD'; Girish Kulkarni, MD'; Alexandre Zlotta, MD'; \\ Neil Fleshner, MD'
}

\begin{abstract}
'University Health Network, University of Toronto, Toronto, ON; ${ }^{2}$ University of Western Ontario, London, ON; ${ }^{3}$ Acadia University, Wolfville, NS; ${ }^{4}$ McGill University, Montreal, QC; ${ }^{5 S}$ Sunnybrook Health Sciences Centre, Toronto, ON; Canada
\end{abstract}

Cite as: Can Urol Assoc J 2017;11 (3-4):118-22. http://dx.doi.org/10.5489/cuaj.4182

\section{Abstract}

Introduction: Repeat prostate biopsies in active surveillance patients are associated with significant complications. Novel imaging and blood/urine-based non-invasive tests are being developed to better predict disease grade and volume progression. We conducted a theoretical study to determine what test performance characteristics and costs would a non-invasive test(s) require in order for patients and their physicians to comfortably avoid biopsy.

Methods: Surveys were administered to two populations to determine an acceptable false-negative rate and cost for such test(s). Active surveillance patients were recruited at time of followup in clinic at Princess Margaret Cancer Centre. Physician members of the Society of Urological Oncology were targeted via an online survey. Participants were questioned about their demographics and other characteristics that might influence chosen error rates and cost.

Results: 136 patients and 670 physicians were surveyed, with 130 $(95.6 \%)$ and 104 (15.5\%) responses obtained, respectively. A vast majority of patients $(90.6 \%)$ were comfortable with a non-invasive test(s) in place of biopsy, with $64.8 \%$ accepting a false-negative rate of $5-20 \%$. Most physicians (93.3\%) were comfortable with a non-invasive test, with $77.9 \%$ accepting a rate of $5-20 \%$. Most patients and physicians felt that a cost of less than $\$ 1000$ per administration would be reasonable.

Conclusions: Most patients/physicians are comfortable with a non-invasive test(s). Although a 5\% error rate seems acceptable to many, a substantial subset feels that $99 \%$ or higher negative predictive value is required. Thus, a personalized approach with shared decision-making between patients and physicians is essential to optimize patient care in such situations.

\section{Introduction}

Active surveillance (AS) is an increasing management of choice for many patients with low-risk, localized prostate cancer. AS protocols usually involve confirmatory transrectal ultrasound-guided biopsy (TRUS-BX), followed by serial biopsies every two to five years or more frequently, if clinically indicated. ${ }^{1}$ There is increasing concern regarding serial TRUS-BX, as repeated TRUS-BX is associated with commonly cited complications such as anxiety, pain, hematuria, hematospermia, and rarely, rectal bleeding. ${ }^{2,3}$ Perhaps more important, has been the rising incidence of TRUS-BX associated septicaemia and even erectile dysfunction. ${ }^{4,5}$

Over the past 10 years, increasing attention has been placed on developing non- or minimally invasive tests in order to determine if prostate biopsy is needed among men with elevated levels of prostate-specific antigen (PSA). Blood and urine biomarkers, such as $4 \mathrm{KScore}{ }^{\circledR}$, Prostate Health Index, and Prostate Cancer Antigen 3 (PCA3) have entered clinical practice and have had inconsistent uptake. In addition, modern techniques of prostate imaging, especially multiparametric magnetic resonance imaging $(\mathrm{mpMRI})$ are also being touted. In light of the advances in biomarker and imaging technology, coupled with AS patients' (and their doctors') increasing aversion towards TRUS-BX, we decided to conduct a theoretical study to determine what test performance characteristics would a non-invasive test or tests need to achieve in order for patients and their physicians to comfortably avoid biopsy. 


\section{Methods}

\section{Study design}

After receiving institutional review board approval, data was collected from consecutively consenting AS patients with histologically confirmed prostate cancer at time of visit to the prostate cancer clinic at Princess Margaret Cancer Centre beginning August 2015 for a period of four months. Responses from urological oncologists worldwide were obtained in March 2016 by circulating an online survey via the Society of Urologic Oncology (SUO) using SurveyMonkey ${ }^{\circledR}$. Members of SUO were provided with a link to an informational page about the survey. Electronic consent was needed to progress to the survey, and repeat survey entries were prohibited to decrease the likelihood of repeat participants.

\section{Survey instrument}

Survey development was modeled on a previously validated survey administered to health professionals on acceptable levels of risk of major cardiac events following discharge from the emergency department. ${ }^{6}$ The survey has content validity, and prior to distribution, four physicians, three research staff, and four administrative staff reviewed the instrument for comprehension and language fine-tuning. Separate but overlapping survey tools were used for each of the populations. The patient survey consisted of seven questions and required approximately 10 minutes to complete. The physician survey contained 10 questions and required about 15 minutes to complete. In addition to collecting nonidentifying demographic information, patients were questioned about number of prior biopsies, what false-negative (FN) rate they would accept for such tests(s), and acceptable out-of-pocket expenditure. Informed, trained clinical research staff were on hand to provide survey assistance if clarification was needed, particularly if the participant had difficulty with understanding the concept of a FN rate. Physicians were questioned about demographics, practice location and setting, number of years since they finished residency training, number of years of involvement in care of patients managed with AS, tests used in management of patients on AS, and acceptable FN rate and expenses for such test(s).

\section{Statistical analyses}

Summary statistics were performed using frequencies and proportions for categorical variables. Differences between patient and physician choices for test(s) FN rate and cost were tested using the Chi-square test. Similarly, associations between demographic variables and value of $\mathrm{FN}$ rate or test(s) expense chosen were tested using the Chi-square test. Analyses were performed using SPSS ${ }^{\circledR}$, version 23.0. All analyses used two-sided tests with significance set at $p=0.05$.

\section{Results}

\section{Populations}

One hundred and thirty-six patients were approached and 130 responses were obtained (response rate 95.6\%). Most patients were 60-80 years old. The demographic profile of our cohort is typical of that of our urban population. The majority continued their education beyond the high school level, over half had an annual income exceeding \$50 000, and most were married or in a committed long-term relationship. In terms of prior biopsies, $78.5 \%(102 / 130)$ had three prior biopsies or less (Table 1).

Of the 670 physicians surveyed, 104 responses were obtained (response rate $15.5 \%$ ). Physicians were of varying age groups, with $90.4 \%$ (94/104) of respondents indicating that the U.S. was their country of current practice. The majority were practicing in a metropolitan area and in a group practice setting (including hospitals). Almost 80\% (82/104) had urology-oncology fellowship training. Participants varied with respect to years since finishing residency training, with $23.1 \%(24 / 104)$ indicating that they graduated less than five years ago, and $20.2 \%(21 / 104)$ more than 30 years ago. The majority had managed patients with AS for 15 years or less (Table 2). Physicians were also asked about tests they currently use in management of patients with prostate cancer on active surveillance. Most currently use PSA and prostate biopsy.

\section{Patient and physician acceptable FN rates for non-invasive test(s)}

\section{Patient responses}

In terms of patient tolerance for FN results, 9.4\% (12/128) were not comfortable with a non-invasive test(s) in place of prostate biopsy. However, 64.8\% (83/128) were accepting of a $\mathrm{FN}$ rate of $5 \%$ or worse. The remaining $25.8 \%$ (33/128) of respondents preferred a FN rate of $1 \%$ or lower (Table 3 ). There was no association between surveyed patient characteristics and choice of $\mathrm{FN}$ rate.

\section{Physician responses}

In terms of physician tolerance for $\mathrm{FN}$ results, $6.7 \%$ (7/104) were not comfortable with a non-invasive test(s) in place of prostate biopsy. Approximately $77.9 \%$ (81/104) indicated that they would accept a FN rate of $5 \%$ or worse. The remaining $15.4 \%(16 / 104)$ preferred a $\mathrm{FN}$ rate of $1 \%$ or lower (Table 3). There was no association between queried physician characteristics and choice of FN rate. No statis- 
Sayyid et al.

\begin{tabular}{|c|c|}
\hline Characteristic & n (\%) \\
\hline \multicolumn{2}{|l|}{ Age (years) $(n=130)$} \\
\hline Under 50 & $2(1.5)$ \\
\hline $50-59$ & $21(16.2)$ \\
\hline $60-69$ & $64(49.2)$ \\
\hline $70-79$ & $38(29.2)$ \\
\hline 80 or older & $5(3.8)$ \\
\hline \multicolumn{2}{|l|}{ Highest level of education ( $n=126$ ) } \\
\hline High school & 19(15.1) \\
\hline College degree or certificate & $27(21.4)$ \\
\hline University undergraduate degree & $47(37.3)$ \\
\hline $\begin{array}{l}\text { Post-graduate (Master's, PhD, MD, law } \\
\text { school) }\end{array}$ & $33(26.2)$ \\
\hline \multicolumn{2}{|l|}{ Annual income $(n=130)$} \\
\hline$<\$ 25000$ & $17(13.1)$ \\
\hline$\$ 25000-49999$ & $16(12.3)$ \\
\hline$\$ 50000-74999$ & $28(21.5)$ \\
\hline$\geq 75000$ & $54(41.5)$ \\
\hline Prefer not to answer & 15 (11.5) \\
\hline \multicolumn{2}{|l|}{ Marital status $(n=128)$} \\
\hline Single & 16 (12.5) \\
\hline Married (or committed long-term relationship) & 92 (71.9) \\
\hline Separated/divorced & 15 (11.7) \\
\hline Widowed & $5(3.9)$ \\
\hline \multicolumn{2}{|l|}{ Previous number of biopsies $(n=130)$} \\
\hline 1 & $38(29.2)$ \\
\hline $2-3$ & $64(49.2)$ \\
\hline $4-5$ & $18(13.8)$ \\
\hline$>5$ & $10(7.7)$ \\
\hline
\end{tabular}

tically significant differences existed between patient and physician choices $(p=0.29)$.

\section{Patient and physician acceptable costs for non-invasive test(s)}

\section{Patient response}

About $8.6 \%$ (11/128) of patient respondents would prefer a fully insured biopsy to any out-of-pocket expenses (at the 100 dollar level). Approximately two-thirds of patients responded that the test(s) must cost less than $\$ 500$ (Table 4). There was significant association between highest level of education and acceptable out-of-pocket expense $(p=0.01)$, with those having a university undergraduate $(p=0.01)$ or a post-graduate $(p=0.04)$ degree more likely to accept a higher out-of-pocket expense compared to those whose highest level of education was at the high school level. Similarly, patient annual income was associated with acceptable outof-pocket expense $(p<0.01)$, with those having an annual income of greater than $\$ 75000(p<0.01)$ more likely to choose a higher out-of-pocket expense, compared to those with an annual income less than \$25000.

\begin{tabular}{|c|c|}
\hline Characteristic & n (\%) \\
\hline \multicolumn{2}{|l|}{ Age (years) $(n=104)$} \\
\hline Under 40 & $34(32.7)$ \\
\hline $40-49$ & $22(21.2)$ \\
\hline $50-59$ & $18(17.3)$ \\
\hline $60-69$ & $20(19.2)$ \\
\hline 70 or older & $10(9.6)$ \\
\hline \multicolumn{2}{|l|}{ Country of current practice $(n=104)$} \\
\hline USA & $94(90.4)$ \\
\hline Canada & $6(5.8)$ \\
\hline Other & $4(3.8)$ \\
\hline \multicolumn{2}{|l|}{ Practice location $(n=104)$} \\
\hline Rural (population <1000) & $0(0)$ \\
\hline Suburban (population 1000-29 999) & $2(1.9)$ \\
\hline Urban (population 30 000-99 999) & $12(11.5)$ \\
\hline Metropolitan (population $\geq 100000$ ) & 90 (86.5) \\
\hline \multicolumn{2}{|l|}{ Physician practice setting ( $n=104)$} \\
\hline Solo practice & $5(4.8)$ \\
\hline Group practice (including hospital setting) & 99 (95.2) \\
\hline \multicolumn{2}{|l|}{ Urology-oncology fellowship training $(n=104)$} \\
\hline Yes & $82(78.8)$ \\
\hline No & $22(21.2)$ \\
\hline \multicolumn{2}{|l|}{ Years since finished residency training $(n=104)$} \\
\hline Less than 5 & $24(23.1)$ \\
\hline $5-9$ & 16 (15.4) \\
\hline $10-14$ & 14 (13.5) \\
\hline $15-19$ & $5(4.8)$ \\
\hline $20-24$ & 12 (11.5) \\
\hline $25-29$ & 12 (11.5) \\
\hline 30 or more & $21(20.2)$ \\
\hline \multicolumn{2}{|l|}{$\begin{array}{l}\text { Years of involvement in care of prostate cancer } \\
\text { patients on active surveillance }(n=104)\end{array}$} \\
\hline Less than 5 & $21(20.2)$ \\
\hline $5-9$ & $32(30.8)$ \\
\hline $10-14$ & $24(23.1)$ \\
\hline $15-19$ & $9(8.7)$ \\
\hline $20-24$ & $5(4.8)$ \\
\hline $25-29$ & $4(3.8)$ \\
\hline 30 or more & $9(8.7)$ \\
\hline
\end{tabular}

\section{Physician response}

A small minority of physicians (3/102) indicated that they do not believe that the benefit is enough to warrant any expenditure. Approximately half (50/103) responded that the tests(s) should cost less than $\$ 500$, with $76.7 \%$ (79/103) indicating that a cost up to $\$ 1000$ would be acceptable (Table 4). There was no association between queried physician characteristics and choice of acceptable costs. 
Acceptable false-negatives in AS patients

\begin{tabular}{|c|c|c|c|c|c|c|}
\hline \multirow[t]{2}{*}{ Rate } & \multicolumn{3}{|c|}{ Patients } & \multicolumn{3}{|c|}{ Physicians } \\
\hline & $\mathbf{n}$ & $\%$ & Cumulative \% & $\mathbf{n}$ & $\%$ & Cumulative \% \\
\hline $20 \%$ & 17 & 13.3 & 13.3 & 3 & 2.9 & 2.9 \\
\hline $5 \%$ & 39 & 30.5 & 64.8 & 40 & 38.5 & 77.9 \\
\hline $1 \%$ & 23 & 18.0 & 82.8 & 13 & 12.5 & 90.5 \\
\hline Total & 128 & 100.0 & 100.0 & 104 & 100.0 & 100.0 \\
\hline
\end{tabular}

\section{Discussion}

Although TRUS-BX has been a mainstay of prostate cancer diagnosis for over 25 years, changing technologies, as well as increased rates of biopsy-associated complications, mandate that we explore alternate modes of testing. In our view, the AS population is a particularly ripe population of patients for studying alternatives to TRUS-BX. They are men who will be subjected to multiple serial biopsies and as they have, by definition, already had a biopsy, the conditional probability of missing large and high-grade tumours is less than in men who are at risk and have never had a biopsy. This group is also unique in that evidence suggests that such men are at higher risk for biopsy-associated sepsis, hospital admission, and perhaps even erectile dysfunction. Ehdale et al demonstrated that men who have had prior biopsies were $30 \%$ more likely to have TRUS-BX-associated sepsis with each subsequent biopsy. ${ }^{4}$ Furthermore, data from two studies have suggested that men subjected to multiple biopsies may also be at higher risk for erectile dysfunction, ${ }^{5,7}$ which may be due to neurovascular bundle trauma. Others have not corroborated this observation..$^{8,9}$

In conducting this survey, we felt it important to define the needed test characteristics for an alternative to serial TRUS-BX among men on AS, as the scientific biomarker and imaging breakthroughs continue to emerge and improve. When we began this study, we expected that a particular value of false-negativity (i.e., the chance of missing a signifi- cant cancer via a biopsy alternate) would emerge to guide patients, physicians, and biomarker companies. In fact, our survey has revealed more of a personalized approach to this dilemma

Based on our results, most patients and physicians (about 90\%) are comfortable with a non-invasive test(s) as an alternative to prostate biopsy for men on AS. Not surprisingly, both groups required that the test be sensitive, with a $\mathrm{FN}$ rate of $5 \%$ or less $(65 \%$ for patients and $78 \%$ for physicians). However it must be stated that about $25 \%$ of patients and $15 \%$ of physicians feel that the test must achieve a negative predictive value of $99 \%$ or even greater.

In light of these data, our feeling is that unless a test achieves a negative predictive value of $99 \%$, a personalized approach will be needed in the clinic. In other words, physicians must explain to their patients the error rate and determine their degree of comfort in terms of missing critical test results when weighed against the discomfort and complications of the procedure itself. The paradigm for this approach has been evaluated before. Yamamoto et al reported an overwhelming patient preference for involvement in decision-making regarding procedures such as pediatric occult bacteremia workup and sedation for laceration repair. ${ }^{10,11}$ This emphasizes the importance of patient education and shared decision-making between patients and physicians.

The strength of our study is our very high patient response rate and face-to-face questionnaire administration. Using the

\begin{tabular}{|c|c|c|c|c|c|c|}
\hline$<\$ 100$ & 29 & 22.7 & 22.7 & 7 & 6.8 & 6.8 \\
\hline$\$ 500-999$ & 14 & 10.9 & 75.0 & 29 & 28.2 & 76.7 \\
\hline$\$ 1000-1999$ & 6 & 4.7 & 79.7 & 17 & 16.5 & 93.2 \\
\hline Do not believe benefit is enough to warrant any expenditure & 11 & 8.6 & 100.0 & 3 & 2.9 & 100.0 \\
\hline Total & 128 & 100.0 & 100.0 & 103 & 100.0 & 100.0 \\
\hline
\end{tabular}


Sayyid et al.

AS population is also critical, as they have experienced prior biopsy and are the ultimate subjects we are proposing to apply this paradigm on. This is also the first study to assess this important topic.

As in any study, biases may hinder generalizability. One of our limitations is responder bias. As with many surveys, only approximately $15.5 \%$ of physicians completed our questionnaire. It remains possible that a different outcome could emerge if a more complete cohort were sampled, especially non-oncology-based urologists. However in this case, it is the patient, not the physician, who ultimately consents to a test or procedure. Thus, the patient responses are more relevant in this context. Still, our patient cohort may not be generalizable either. They are patients who are largely urban, educated, Canadian, and Caucasian. Clearly, subcohorts of men with different demographic characteristics may be different and can be the subject of future research. We also are mindful that we have asked Canadian patients, who very rarely pay out-of-pocket for healthcare, to estimate acceptable costs for themselves, and compared this to a largely U.S.-based physician group. Although this can be a criticism, the fact that the net amounts are comparable make it likely that this would be the right ballpark for pricing, should and when these hypothetical tests become available.

In conducting this study, we noted that many patients appear to understand risk and use rational thresholds for a test. However, a minority answered in a way that suggests a lack of understanding about risk and the consequences of unnecessary biopsy and delayed cancer diagnosis. This emphasizes the importance of education of such patients in the future.

\section{Conclusion}

To our knowledge, this is the first survey of patients and physicians regarding their perspectives on non-invasive test(s) in lieu of biopsy for followup of AS prostate cancer patients. It appears that a vast majority of patients/physicians would be comfortable with a non-invasive test(s). Although a 5\% FN rate seems acceptable to many, a substantial subset of men/ physicians feel that $99 \%$ or higher negative predictive value is required. Given these findings, a personalized approach with shared decision-making between patients and physicians is essential to optimize patient care in such situations.
Competing interests: Dr. Diamond has investments in Johnson \& Johnson. Dr. Hersey has received speaker honoraria from Janssen. Dr. Klotz has received honoraria and research funding from AbbVie, Amgen, Astellas, Aventis, Ferring, and Janssen. Dr. Finelli has been an advisor for Amgen, Astellas, and Janssen; and has received honoraria from AbbVie, AstraZeneca, and Ferring. Dr. Hamilton has been an advisor for AbbVie, Astellas, Bayer, and Janssen. Dr. Kulkarni has been an advisor for Amgen, Astellas, Bayer, Ferring, and Janssen; and has received educational grants from AbbVie and Sanofi. Dr. Zlotta has been an advisor for Ferring, LLC, Sanofi, and 3DBiopsy. Dr. Fleshner has been an advisor for AbbVie, Amgen, Astellas, Bayer, Ferring, Janssen, and Sanofi; has received grants from AbbVie, Amgen, Astellas, Bayer, the Canadian Cancer Researrh Institute, Ferring, Hybridyne Imaging Technologies, Janssen, and Sanofi; and has participated in clinical trials for Astellas, Bavarian Nordic, Bayer, Ferring, Janssen, Medivation, Nucleix, Progenics, Sanofi, and Spectracure AB. The remaining authors report no competing personal or financial interests.

This paper has been peer-reviewed.

\section{References}

1. Chen RC, Rumble RB, Loblaw DA, et al. Active surveillance for the management of localized prostate cancer (Cancer Care Ontario Guideline): American Society of Clinical Oncology clinical practice guideline endorsement. J Clin Oncol 2016;34:2182-90. https://doi.org/10.1200/JC0.2015.65.7759

2. Loeb $S$, Vellekoop A, Ahmed HU, et al. Systematic review of complications of prostate biopsy. Eur Urol 2013;64:876-92. https://doi.org/10.1016/i.eururo.2013.05.049

3. Wade J, Rosario DJ, Macefield RC, et al. Psychological impact of prostate biopsy: Physical symptoms, anxiety, and depression. J Clin Oncol 2013;31:4235-41. hitps://doi.org/10.1200/JC0.2012.45.4801

4. Ehdale $B$, Vertosick $E$, Spaliviero $M$, et al. The impact of repeat biopsies on infectious complications in men with prostate cancer on active surveillance. J Urol 2014;191:660-4. https://doi.org/10.1016/i. juro.2013.08.088

5. Fuijta K, Landis P, McNeil, BK et al. Serial prostate biopsies are associated with an increased risk of erectile dysfunction in men with prostate cancer on active surveillance. J Urol 2009;182:2664-9. https://doi.org/10.1016/i.juro.2009.08.044

6. Than $M$, Herbert $M$, Flaws $D$, et al. What is an acceptable risk of major adverse cardiac event in chest pain patients soon after discharge from the emergency department? A clinical survey. Int I Cardiol 2013;166:752-4. https://doi.org/10.1016/i.i.jard.2012.09.171

7. Whitson JM, Murray KS, Thrasher JB. Prostate biopsy is associated with an increased risk of erectile dysfunction. J Urol 2016;196:21-3. https://doi.org/10.1016/i.juro.2016.04.002

8. Pepe $P$, Pietropaolo $F$, Dibenedetto $G$, et al. Erectile function after repeat saturation prostate biopsy: Our experience in 100 patients. Arch Ital Urol Androl 2013;85:130-2. https://doi.org/10.4081/ aiva.2013.3.130

9. Braun $K$, Ahallal $Y$, Sioberg DD, et al. Effect of repeated biopsies on erectile function in men on active surveillance for prostate cancer. J Urol 2014;191:744-9. https://doi.org/10.1016/i.juro.2013.08.054

10. Yamamoto GL. Application of informed consent principles in the emergency department evaluation of febrile children at risk for occult bacteremia. Hawaii Med J 1997;56:313-7, 320-2.

11. Yamamoto LG, Young LL, Roberts JL. Informed consent and parental choice of anesthesia and sedation for the repair of small lacerations in children. Am J Emerg Med 1997;15:285-9. https://doi.org/10.1016/ S0735-6757(97)90017-6

Correspondence: Dr. Neil Fleshner, University Health Network, University of Toronto, Toronto, ON, Canada; neil.fleshner@uhn.ca 